\title{
ОЦЕНКА ЧЕЛОВЕЧЕСКОГО РАЗВИТИЯ В РОССИЙСКОЙ ФЕДЕРАЦИИ
}

\author{
(C) 2021 Искаков Марат Ришатович \\ аспирант Института экономики, финансов и бизнеса \\ Башкирский государственный университет, Россия, Республика Башкортостан, Уфа \\ E-mail: marat.iskakov1995@yandex.ru \\ () 2021 Янгирова Елена Ирековна \\ доктор экономических наук, профессор, \\ заведующий кафедрой управления проектами и маркетинга \\ Башкирский государственный университет, Россия, Республика Башкортостан, Уфа \\ E-mail:beglovaelena75@mail.ru
}

В статье проводится оценка человеческого развития в Российской Федерации. Проанализированы данные индекса человеческого развития, рассчитанного по методике программы развития ООН, за 2015-2020 гг. Проведен анализ влияния изменений составляющих человеческого развития в регионах Российской Федерации на рассчитанный индекс человеческого развития. Определено влияние креативной экономики на формирование ВВП страны.

Ключевые слова: человеческого развитие, экономический рост, индекс человеческого развития, модернизированный индекс человеческого развития, продолжительность жизни населения, креативная экономика, человеческий потенциил.

\section{Введение}

Объект: человеческое развитие в Российской Федерации.

Предмет: оценка человеческого развития Российской Федерации с помощью разработанного автором модернизированного индекса человеческого развития.

Цель: исследование составляющих модернизированного индекса человеческого развития с целью выявления причины их низких показателей.

Гипотеза: выявленные низкие показатели составляющих модернизированного индекса человеческого развития, такие как «креативная» экономика и управленческий, научно-кадровый потенциал Российской Федерации являются потенциалом роста для человеческого развития.

В период пандемии COVID-19 человеческое общество впервые испытало невероятный спад человеческого развития и экономического роста, что обусловлено высоким уровнем смертности, замедлением развития экономики и вытеснением более 100 миллионов людей в мире за черту бедности. Аналитический центр при правительстве РФ во главе с профессором НИУ ВШЭ Леонидом Марковичем Григорьевым отмечает, что в 2020 году общество ощутило обратную сторону высокого уровня человеческого развития, деятельность человека, как главной составляющей развития об- щества и двигателя прогресса, в свою очередь, может привести к взаимосвязанному планетарному и социальному дисбалансу в мире [1]. Как отмечает С.А.Морозов, обратный эффект человеческого развития повлёк за собой стагнацию экономического роста, что вызвало во всём мире не только экономический, но и социальный кризис [11].

Российское общество также не готово было к стремительно развивающейся ситуации, связанной с распространением COVID-19. Экономисты О.А.Левшукова, А.С.Матвеев, Д.П.Позоян считают, что ограничительные меры, введённые во время пандемии, негативно отразились на экономической ситуации в стране: снизилась предпринимательская активность, покупательская способность и инвестиционная активность предпринимательской деятельности, снизились доходы населения и возрос уровень безработицы [13].

По мнению Шматовой Ю.Е., пандемия 2020-го года показала, насколько хрупким может быть социально-экономическое состояние стран в критических ситуациях, происходящих в мире [16]. Дисбаланс, который возник между разрушающей и созидательной деятельностью человека, оказался неустойчивым в быстроразвивающемся человеческом обществе. Найдя баланс в этой диспропорции человек должен осознать свою ведущую роль в эпохе человеческого развития. 


\section{Методические основания работы}

Для оценки уровня человеческого развития авторами была использована методика, разработанная ПРООН и модернизированный разработанный авторами метод оценки человеческого развития.

Показателем уровня человеческого развития по всему миру является индекс человеческого развития, рассчитанный по методике, разработанной ПРООН в 1990 г. Данные о продолжительности жизни, уровне образования и достойном уровне жизни, полученные за прошедший год, анализируются в текущем году. Результаты анализа и расчёта ИЧР для всех стран выпускаются в Докладе о человеческом развитии ПРООН каждый год с 1990 г. В Докладе подробно изложены данные индикаторов и факторов человеческого развития и приведён межстрановый рейтинг по рассчитанному ИЧР.

На настоящий момент был издан Доклад о человеческом развитии 2020 г, который анализирует данные 2019 г. Показатели значения ИЧР для Российской Федерации в 2014-2019 гг. для анализа были взяты из Докладов о человеческом развитии ПРООН 2015-2020 гг. и указаны в таблице 1 . Как видно из таблицы 1 значение ИЧР в динамике увеличивается, в 2018-2019 гг. происходит стагнация индекса человеческого развития, что обусловлено множеством социальных, демографических и экономических факторов. Чтобы определить какой именно фактор непосредственно влияет на уровень человеческого развития необходимо разобрать ИЧР по индикаторам и провести анализ.

Российская Федерация отстает от западных стран по уровню выпуска продукции на душу населения, что является, в свою очередь, преградой к инновационному развитию не только человеческого потенциала, но и экономики стра- ны [2]. Также негативными факторами, которые косвенно влияют на человеческое развитие РФ, являются высокий уровень инфляции, бюрократичная структура управления страны и сформировавшихся крупных монополистических организаций. Невысокая продолжительность жизни - одна из проблем невысокого показателя индекса человеческого развития в РФ. Причинами невысокой продолжительности жизни в РФ являются неблагоприятная экологическая ситуация в стране, высокая смертность от заболеваний, большое количество несчастных случаев, высокий уровень преступности в РФ. Главный основополагающий фактор, оказывающий сильное влияние на индекс человеческого развития - это образование. В него входят недостаточно сильная мотивация обучающихся и осуществляющих обучение, низкая заработная плата учителей и преподавателей, отсутствие современной учебной лабораторной базы.

В 2014-2018 гг. происходит последовательное приращение индекса человеческого развития, в 2014 г. ИЧР относился к высокому показателю ИЧР в мире, начиная с 2015 г. показатель ИЧР в РФ относится уже к очень высокому показателю ИЧР в мире. В 2018-2019 гг. показатели индекса человеческого развития равны, что обусловлено незначительными изменениями в индикаторах, содержащихся в формуле расчёта ИЧР. В 2019 г. по сравнению с 2018 г. наблюдается незначительное уменьшение ожидаемой продолжительности обучения и незначительное увеличение ожидаемой продолжительности жизни и ВНД на душу населения.

По данным таблицы 1 и рисунка 1 в РФ происходит в 2014-2019 гг. постепенное незначительное увеличение ожидаемой продолжительности жизни. Но ожидаемая продолжительность жизни в Российской Федерации имеет достаточ-

Таблица 1. Показатели значения ИЧР и его индикаторов для Российской Федерации в 2014-2019 гг.

\begin{tabular}{|c|c|c|c|c|}
\hline Исследуемый год & Значение ИЧР & $\begin{array}{c}\text { Ожидаемая продол- } \\
\text { жительность жизни, } \\
\text { в годах }\end{array}$ & $\begin{array}{c}\text { Ожидаемая про- } \\
\text { должительность } \\
\text { обучения, в годах }\end{array}$ & ВНд, в долл. США \\
\hline 2019 & 0,824 & 71,7 & 15,0 & 28260 \\
\hline 2018 & 0,824 & 71,5 & 15,5 & 27980 \\
\hline 2017 & 0,816 & 71,2 & 15,5 & 25230 \\
\hline 2016 & 0,815 & 70,09 & 15,2 & 24890 \\
\hline 2015 & 0,804 & 70,06 & 15,0 & 23420 \\
\hline 2014 & 0,798 & 70,03 & 14,7 & 24910 \\
\hline
\end{tabular}

Источник: Доклады о человеческом развитии за 2015-2020 гг. 


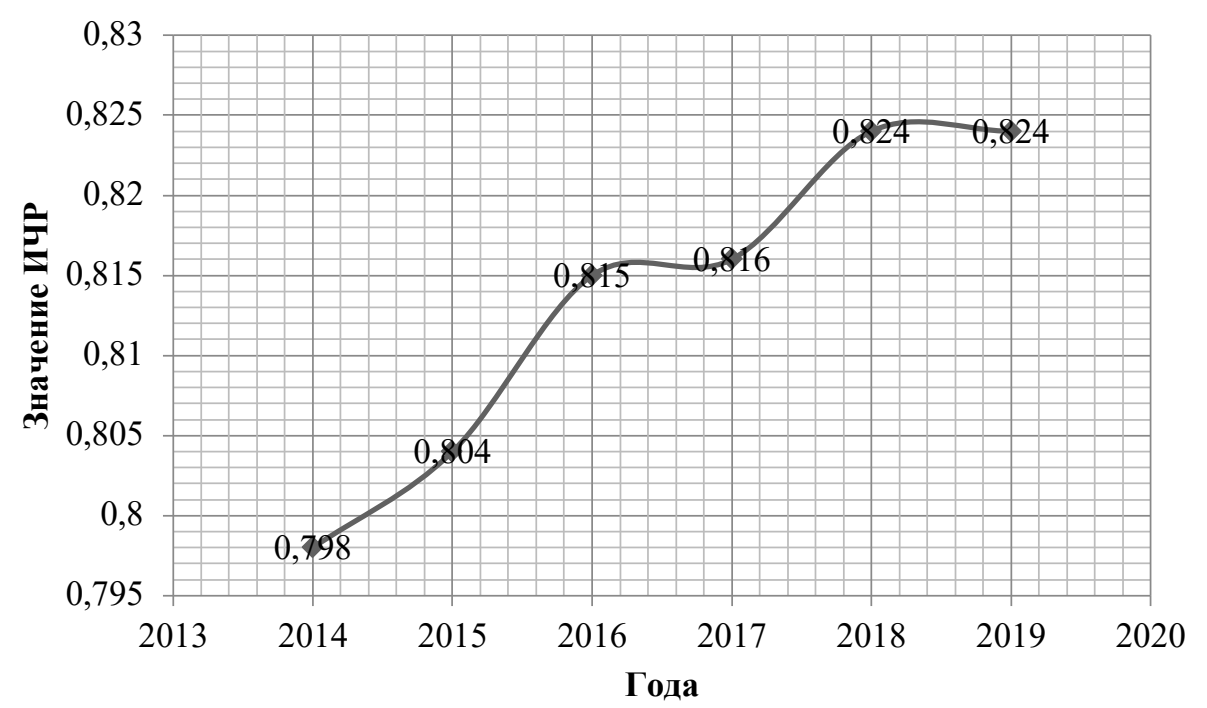

Puc. 1. Динамика значения ИЧР для РФ в 2014-2019 гг. Источник: Данные таблицы 1.

но низкое значение по сравнению с мировой статистикой. Основная причина низкой продолжительности жизни в России - экологическая ситуация в стране, неэффективность проводимой социально-экономической политики и целого ряда демографических проблем. Здоровье населения в Российской Федерации в текущей эпидемиологической ситуации подвергается серьёзному воздействию. В расчёте индекса человеческого развития существует тесная взаимосвязь между здоровьем, измеряемой ожидаемой продолжительностью жизнью населения, и доходами на душу населения [6].

Анализ влияния индикаторов на индекс человеческого развития

Высокий уровень здоровья населения, измеряемый значительными инвестициями в здравоохранение и его доступностью, положительно воздействуют на уровень доходов населения. Инвестиции в здравоохранение выражаются в высокой производительности труда работников и в качестве выполнения их работы, что приводит к экономическому росту в стране [7].

Хочется отметить, что отношение государственных расходов на здравоохранение к ВВП, отражающее отношение государственной социально-экономической политики, связано с поддержанием здоровья населения и составляет 0,75\% на 2018 г. Среднее значение данного показателя для европейских и экономически развитых стран составляет 8-9\% от ВВП, что значительно больше имеющегося показателя в РФ.
Огромные различия в величине государственных расходов на здравоохранение обусловлены технологическим отставанием российской медицины от европейских стран и неэффективностью системы российского здравоохранения.

Главенствующим фактором индекса человеческого развития в России является высокий уровень образования населения [9]. Уровень охвата образованного населения в России - один из самых высоких в мире. Высокий показатель образования в России подчёркивают эксперты ООН. Однако нужно отметить, что удельный вес государственных расходов на поддержание образования ниже, чем в странах с отстающим индексом человеческого развития, что в дальнейшем может стать причиной негативного влияния на качество образования.

Согласно статистике, происходит сокращение численности студентов, обучающихся по программе высшего образования в расчёте на тысячу человек населения, в 1,5 раза в период с 2014 по 2019 гг. Данная закономерность связана со снижением доступности высшего образования, так как уровень жизни россиян за последние 5 лет имеет отрицательную динамику.

Уровень жизни в Российской Федерации по сравнению с развитыми европейскими странами не высок. Значение ВНД на душу населения в России в 2,7 раза меньше, чем у Норвегии, которая занимает первое место в рейтинге стран по индексу человеческого развития. Основная причина низкого показателя ВНД - низкая про- 
изводительность труда населения. В странах с высоким ВНД на душу населения на одного занятого, данный показатель выше в 3,3 раза, чем в Российской Федерации.

Низкий показатель уровня жизни населения в Российской Федерации связан с демографическими отклонениями, а также с текущей экономической ситуации в стране. Два данных аспекта могут повлиять на социальную нестабильность и экономическую безопасность в РФ [12]. Как видно из таблицы 2, реальные располагаемые доходы населения России снижаются с каждым годом, незначительное увеличение на десятую долю процента наблюдается в 2018-2019 гг. Положительное влияние на динамику реальных располагаемых доходов в 2019 году оказали следующие факторы: снижение уровня потребительской инфляции (в 2019 г. 3\%, а в 2018 г. 4,3\%), а также снижение долговой нагрузки населения в связи с уменьшением кредитования населения с 22,8 до 18,6\% в 2019 г [1]. Сдерживающими факторами существенного роста реальных располагаемых доходов населения РФ в 2019 г. являются незначительный рост заработной платы по сравнению с предыдущим годом, увеличение ставки НДС с 18 до 20\% и последующий рост потребительских цен.

Оценка уровня человеческого развития в Российской Федерации определяется по методике, изложенной в докладе ПРООН. Расчёт ИЧР и других индексов человеческого развития ведётся в разрезе всей страны и субъектов РФ, что, в свою очередь, свидетельствуют о неравномерности «распределения» человеческого развития в РФ. Лидирующими субъектами с высоким уровнем человеческого развития являются Мо- сква, Санкт-Петербург, Тюменская, Сахалинская и Белгородская область. Высокоразвитыми субъектами РФ являются финансово-экономические центры страны (города федерального значения в связи с существующим высокопрофицитным бюджетированием), сырьевые экспортноориентированные субъекты, а также субъекты с диверсификационной экономикой и субъекты с опорой на обрабатывающую или добывающую промышленность.

Существующий разрыв в показателях ИЧР различных регионов РФ вызывает диспропорцию и общее замедление развития страны и роста экономики. Помимо этого проведя объективную оценку ИЧР невозможно из-за наличия межрегионального неравенства по доходам ВНД, а также из-за существенного дисбаланса в доходах региональных столиц и региональных муниципалитетов.

Наиболее серьёзная проблема заключается в неравномерности индикаторов ИЧР в центральных регионах РФ: при очень высоком уровне образования существует достаточно низкая продолжительность жизни населения и невысокий уровень доходов [10]. В отдалённых регионах РФ ситуация обратная: при низком уровне образования прослеживается высокий уровень продолжительности жизни населения и низкий уровень доходов. Неравномерность индикаторов ИЧР в субъектах РФ существенно искажает уровень человеческого развития. В большинстве регионов разные индикаторы находятся на низком уровне, т.е. каждый субъект РФ должен вводить мероприятия по повышению уровня человеческого развития, исходя из собственных показателей человеческого развития.

Таблиц̧ 2. Динамика доходов населения России в 2014-2019 гг., в\% к предыдущему году

\begin{tabular}{|c|c|c|}
\hline Исследуемый год & Номинальные доходы & Реальные располагаемые доходы \\
\hline 2014 & 106,7 & 98,8 \\
\hline 2015 & 110,4 & 95,6 \\
\hline 2016 & 102,0 & 99,5 \\
\hline 2017 & 103,3 & 100,4 \\
\hline 2018 & 104,0 & 101 \\
\hline 2019 & 106,1 & 109 \\
\hline
\end{tabular}

Источник: Бюллетень о текущих тенденциях российской экономики. Динамика доходов населения // Аналитический центр при правительстве РФ. 2020. № 58. с. 19. 
Модернизированный индекс человеческого развития

Как было доказано в [5], для комплексной оценки уровня человеческого развития необходимо учитывать большее количество его составляющих для формирования реального положения дел в стране и государстве, а также для принятия и разработки стратегии повышения человеческого развития с дальнейшим изменением вектора экономического роста.

Рассчитаем по разработанной методике [5] модернизированный индекс человеческого развития для РФ за период 2015-2019 гг. и сведём результаты расчёта в таблицу 3.
Проанализировав график, изображённый на рисунке 2 , и результаты расчёта разработанного модернизированного индекса человеческого развития, можно сделать вывод, что реальный уровень человеческого развития Российской Федерации меньше на $17,5 \%$, чем ИЧР, определённый по методике ООН. Данная диспропорция возникла в результате неэффективности системы управления социально-ориентированным развитием экономики страны.

Разберём влияние значений индикаторов на значение МИЧР. Как видно из таблицы 3, существуют два индикатора с очень низкими показателями: индикатор потребностей в уважении

Таблица 3. Расчёт модернизированного индекса человеческого развития

\begin{tabular}{|c|c|c|c|c|c|c|}
\hline $\begin{array}{c}\text { Исследуемый } \\
\text { год }\end{array}$ & I health+income & $\mathrm{I}_{\text {sociable }}$ & $\mathrm{I}_{\text {recognition }}$ & $\mathrm{I}_{\text {education }}$ & I bohemia & MHDI \\
\hline 2015 & 0,807 & 0,830 & 0,475 & 0,817 & 0,403 & 0,666 \\
\hline 2016 & 0,811 & 0,832 & 0,470 & 0,826 & 0,403 & 0,668 \\
\hline 2017 & 0,823 & 0,837 & 0,475 & 0,831 & 0,403 & 0,674 \\
\hline 2018 & 0,833 & 0,850 & 0,472 & 0,831 & 0,407 & 0,678 \\
\hline 2019 & 0,836 & 0,847 & 0,480 & 0,823 & 0,401 & 0,677 \\
\hline
\end{tabular}

Источник: Приведённые показатели рассчитаны авторами на основании собранных в декабре 2021 г. данных из Докладов о человеческом развитии 2015-2020 гг. по собственной разработанной в [5] методике.

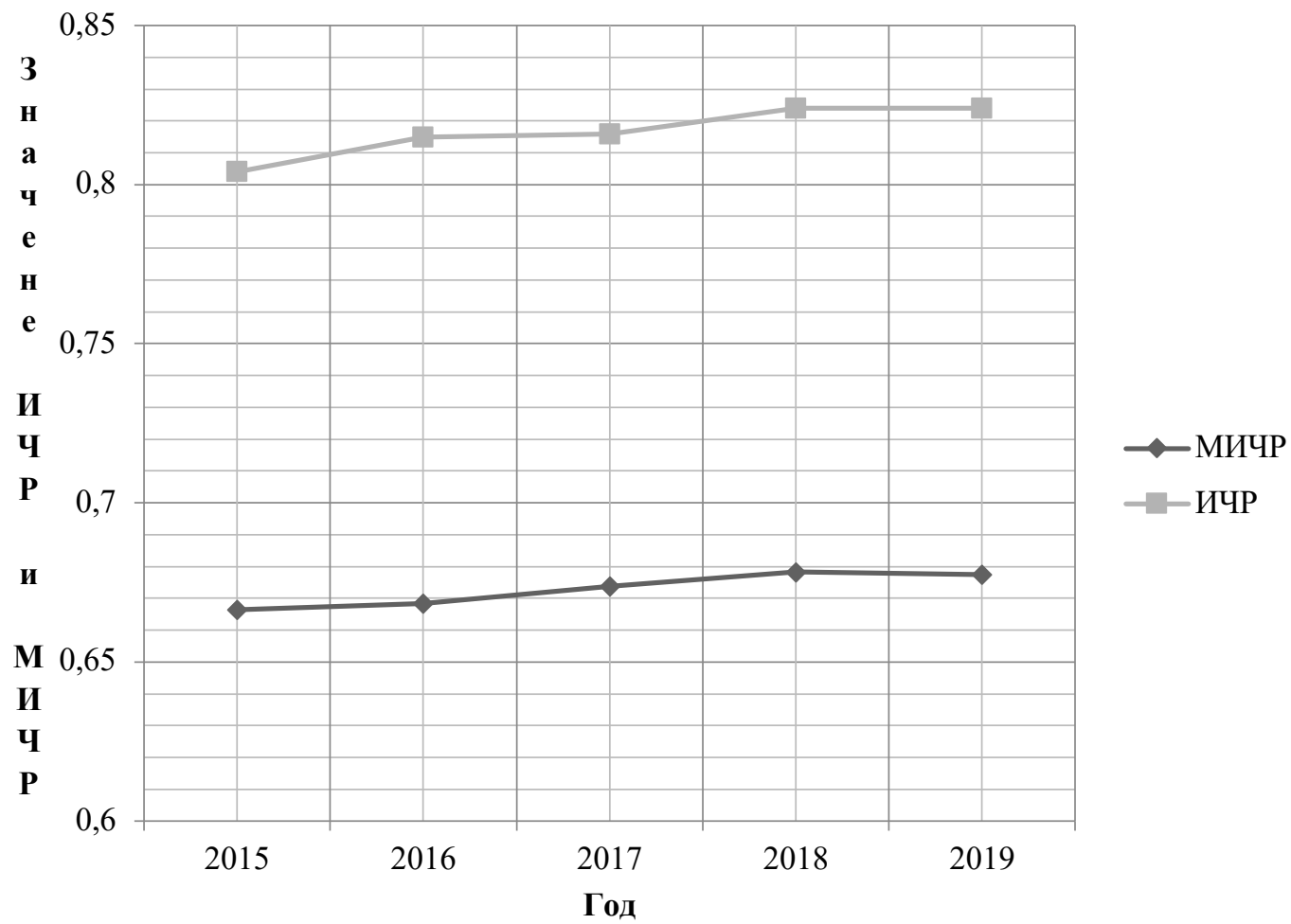

Рuc. 2. Сравнительный анализ ИЧР и модернизированного ИЧР Источник: график построен на основании данных таблицы 1 и 3. 
и признании и индикатор «богемы». Рассмотрим подробнее причины довольно низких показателей данных индикаторов в Российской Федерации.

Провал в индикаторе потребностей в уважении и признании объясняется недостаточным влиянием на человеческое развитие научноуправленческой и творческой интеллигенции в России. В регионе с развитой экономикой колоссальную роль играет присутствие крупного научно-исследовательского центра, а также квалифицированно подготовленных специалистов.

\section{Заключение}

В России на данный момент наблюдается кадровый парадокс. Многие вакансии в различных отраслях заняты, тем не менее, в РФ прослеживается кадровый голод. Причиной всему этому является недостаток квалифицированных специалистов, соответствующих современным требованиям. Они должны обладать способностью анализировать, прогнозировать, умением быстро принимать решение и не бояться брать ответственность. В США, например, количество учёных и инженеров на 100 тыс. человек в 2019 г. составляло более 1100 человек, в то время как в РФ - 138 человек. Количество поступающих в аспирантуру в 2019 году стало в 1,8 раз меньше, чем в 2010 году. В РФ снизилась эффективность аспирантуры, т.е. доля аспирантов, выпустившихся с кандидатской защитой, в 2019 г. равна всего 10,4\% от общего числа обучающихся, что в 3 раза меньше, чем в 2010 г. Данное отклонение наблюдается из-за демографического спада и образовательной реформы 2013 года. Средний возраст кандидатов наук составляет 51 год, докторов наук - 64 года, что свидетельствует о низкой заинтересованности молодёжи в получении учёной степени. Также число научноисследовательских институтов сократилось с 2686 в 2000 г. до 1618 в 2019 г. Таким образом, в научно-исследовательской деятельности наблюдается дефицит аспирантов, исследователей и научных кадров, что свидетельствует о негативной тенденции развития кадрового потенциала науки.

Реальная картина российских управленческих органов показывает необходимость реформирования кадровой политики с целью оптимизации системы управления государством. Негативным фактором страны является недоступность российской управленческой системы, её вертикальность и авторитарность, сложившаяся от исторических традиций российского государства. Всё это влияет на кадровую политику, на управленческие структуры государства. Рекрутинг для государственных и муниципальных служб в реальности осуществляется не посредством подбора специалистов по их профессиональных качествам и личностным навыкам, а по «наследственности». Большая часть сотрудников, занимающая управленческие должности не имеют соответствующего образования, относящееся к профилю, так как не все выпускники вузов находят работу по специальности [8].

В Российской Федерации на 10 тыс. человек населения приходится 163 работника государственных и муниципальных служб, а в таких западных странах, как США, Германия, Канада приходится 178-203 государственных служащих. Сокращение оптимальной численности госслужащих привело к нерациональному распределению служебных обязанностей, снижению результативности труда, несоответствию оплаты труда выполняемому объёму работ.

В современной концепции проводимых реформ в России в области составления управленческой кадровой политики особый аспект занимает улучшение системы профессиональной подготовки управленческого состава. Главенствующей задачей является подготовка и обучение кадров к быстроразвивающемуся миру, повышению уровня личностно-деловых качеств управленческого состава. Данная задача обусловлена необходимостью оптимизации и модернизации профессионального образования, включая принципиально новые методы подходов к самоорганизации и обучению управленческой интеллигенции.

Низкий показатель индикатора «богемы» свидетельствует, что духовная составляющая человеческого развития в РФ не развита. Человеческая креативность в концепции человеческого развития играет ключевую роль в экономическом росте и общественной деятельности государства. Творческая интеллигенция является движущей силой общественных изменений. Данный индикатор можно отнести к основному источнику конкурентоспособности страны на мировом уровне. Так, в США к этому классу принадлежит 38 млн. или 30\% работающих американцев. В Российской Федерации же к классу творческой интеллигенции принадлежит 1,13 млн. или $1,7 \%$ работающих россиян, что в 30 
раз меньше, чем США. Основой населения креативного класса являются люди, занимающиеся искусством и инновациями. Помимо основного кластера креативного населения в него также входят обширная группа креативных специалистов, работающих в бизнесе, финансах, праве, здравоохранении и смежных отраслях деятельности. Главной задачей достижения общественного благополучия является «творческий этос» (общие ценностные установки и культурные ориентации), в котором важны такие показатели, как креативность, индивидуальные особенности и личные заслуги.

Экономика XXI века по сущности является «креативной» экономикой, её главная движущая сила - это креативность. Бурный рост активности «богемы» происходил и наблюдался в XX веке в особенности во второй половине прошлого столетия. В настоящее время креативная деятельность периферийно сосредоточена в центре структуры экономики государства. Научно-художественное слияние образовывают и формируют отдельные индустрии и отрасли. В результате их сочетания возникают совершенно новые формы отраслей, вследствие чего рост экономики всё больше зависит от совместной коллаборации технических инноваций и креативного подхода [3].

Рассматривая инвестиции в «креативную» экономику США, выделим следующие аспекты и количественные параметры:

- систематичное инвестирование в «креативную» экономику, направленное на научноисследовательские работы, начиная с 2010 г. инвестиции в это направление выросли с 405,3 млрд. до 511,1 млрд. долл.;

- непрерывный рост практической составляющей научных исследований в течение последнего десятилетия количество патентов и грантов ежегодно выдаваемых выросли с 422,25 тыс. до 621 тыс.;

- значительный рост числа занятых и работающих людей в сфере культуры.

Ежегодные доходы от «креативной» экономики в США оцениваются в 5,9 трлн. долл. Креативная деятельность в этой стране является лидирующей в мире, её доход превышает 40\% от общей суммы доходов ВВП США. Креативная деятельность в сфере экономики произвела новые методы и технологии, которые вывели США в лидеры на мировом экономическом уровне.

Для Российской Федерации количественные показатели инвестирования в «креативную экономику следующие:

- систематичное инвестирование в «креативную» экономику, направленное на научноисследовательские работы, начиная с 2010 г. инвестиции в это направление снизились с 23 млрд. до 39,9 млрд. долл. По сравнению с показателями в США, уровень инвестирования в научноисследовательские работы меньше в 15,525 раз;

- непрерывный рост практической составляющей научных исследований в течение последнего десятилетия количество патентов и грантов ежегодно выдаваемых выросли с 175 тыс. до 200 тыс., данный показатель меньше практически в 3 раза, чем в США;

- в 2015-2019 гг. численность занятых в отечественной «креативной» экономике поднялась с 4,1 до 4,9 млн. человек.

Ежегодные доходы от «креативной» экономики в России оцениваются в 104,6 млрд. долл., что составляет всего лишь 2,4\% от ВВП страны. В сравнении с США показатель доходов меньше в 56 раз, что наглядно показывает низкий уровень вовлечённости населения России в «креативную» экономику.

Таким образом, существенная разница в показателях ИЧР и МИЧР обусловлена недостаточным научно-управленческим кадровым обеспечением и дефицитом в государстве творческой «креативной» интеллигенции. Данная тенденция обусловлена не только отсутствием необходимой численности кадров, но и незаинтересованностью государства в инвестировании и развитии «креативного» и научного сектора экономики, что в свою очередь способствует негативному эффекту в человеческом развитии РФ и, соответственно, замедляет экономический рост в стране.

\section{Благодарности и финансирование}

Статья представляет результаты исследования по проекту № 20-310-90024 «Разработка факторной модели реалистичного измерения деформации взаимосвязи человеческого развития и экономического роста, оптимизирующей систему государственных мер по формированию человеческого потенциала в Российской Федерации», получившего поддержку Российского фонда фундаментальных исследований по результатам конкурсного отбора научных проектов в качестве победителя конкурса Аспиранты 2020 года. 


\section{Библиографический список}

1. Бюллетень о текущих тенденциях российской экономики. Динамика доходов населения // Аналитический центр при правительстве РФ. 2020. № 58. с. 19.

2. Газибеков С.А. Человеческое развитие как основа современной организации / Газибеков С. A., Aбдусаттарова Р.Ш. // Вестник Таджикского государственного университета права, бизнеса и политики. Серия общественных наук. 2018. № 2. С. 17-23.

3. Джалал Мир Абдул Каюм. Государственная поддержка развития креативного сектора региональной экономики / Джалал Мир Абдул Каюм, Буркальцева Д.Д., Жарова А. Р. // Региональная экономика. Юг России. 2021. № 1. C. 93-104. DOI: 10.15688/re.volsu.2021.1.8.

4. Искаков М.Р. Метод оценки экономического роста через составляющие человеческого развития / М. Р. Искаков // Финансовая экономика. 2020. № 4. С. 377-379.

5. Искаков М.Р. Совершенствование методики расчета индекса человеческого развития / М.Р.Искаков, Е. И. Янгирова // Экономика и управление: научно-практический журнал. 2020. № 6. С. 15-20. DOI: 10.34773/ EU.2020.6.3.

6. Искаков М.Р. Человеческое развитие и экономический рост: сущность и взаимосвязь / М.Р.Искаков, Е.И.Янгирова // Управление экономикой: методы, модели, технологии. Материалы ХХ Международной научной конференции. Уфа. 2020. С. 113-116.

7. Кан В.С. Инвестирование в НИОКР как фактор социально-экономического развития России в условиях глобализации / Кан В.С., Веревка Т.В. // Фундаментальные и прикладные исследования в области управления, экономики и торговли. 2019. С. 384-388.

8. Кореньков А.О. Креативные индустрии как двигатель экономики XXI века / Кореньков А. О. // Экономические системы. 2020. № 1. С. 57-61.

9. Косов М.Е. Российская пирамида инноваций: государственное инвестирование / Косов М.Е., Иванова Я.Я. // Вестник экономической безопасности. 2018. № 2. С. 342-351.

10. Косьмин А.Д. Краткий обзор подходов к измерению человеческого развития / Косьмин А.Д., Кузнецова О.П., Косьмина Е.А. // Российское предпринимательство. 2017. № 10. С. 1615-1636. DOI: 10.18334/ rp.18.10.37968.

11. Морозов С.А. О причинах стагнации Российской экономики / С. А. Морозов // Научный электронный журнал «Меридиан». 2020. № 9. С. 1-13.

12. Лазаревич Н.А. Человеческое развитие в контексте социотехнической коэволюции / Лазаревич Н.А. // Труды БГТУ. 2021. № 1. С. 142-145.

13. Левшукова О.А. Возможные последствия пандемии COVID-19 на развитие экономики России / О.А. Левшукова, А. С. Матвеев, Д. П. Позоян // Естественно-гуманитарные исследования. 2020. № 29. C. 191-194. DOI: 10.24411/2309-4788-2020-10255

14. Половян А. В. Индекс человеческого развития как регулятор экономической сложности страны / А. В. Половян, К.И. Синицына // Вестник института экономических исследований. 2020. № 1. С. 5-13.

15. Рахаева В.В. Влияние пандемии на экономический рост России / В. В. Рахаева, Р. В. Ливанова, Ю.А. Мырксина // Образование и право. 2020. № 11. С. 433-438. DOI: 10.24411/2076-1503-2020-11170.

16. Шматова Ю.Е. Влияние COVID-19 на психическое здоровье населения (как показатель человеческого потенциала): опыт зарубежных исследований / Ю.Е.Шматова // Проблемы развития территории. 2020 . № 4. C. 88-108. DOI: $10.15838 / \mathrm{ptd} / 2020.4 .108 .6$. 